\title{
Textile chemiresistors with sensitive layers based on polymer ionic liquids: applicability for detection of toxic gases and chemical warfare agents
}

Eva Marešová, David Tomeček, Přemysl Fitl, Jan Vlček, Michal Novotný*, Ladislav Fišer, Šárka Havlová, Pavel Hozák, Alexandru Tudor**, Thomas Glennon**, Larisa Florea**, Shirley Coyle**, Dermot Diamond**, Zdeněk Skaličan**, Monika Hoskovcová*** and Martin Vrňata

Department of Physics and Measurements, University of Chemistry and Technology, Technická 5, Prague 6, CZ-166 28, Czech Republic

*Institute of Physics of the Czech Academy of Sciences, Na Slovance 2, Prague 8, CZ182 21, Czech Republic

**Insight Centre for Data Analytics, National Centre for Sensor Research, Dublin City University, Glasnevin, Dublin 9, Ireland

***NBC Defence Institute, University of Defence, Kasárna Dědice, Víta Nejedlého, CZ682 01, Vyškov, Czech Republic

*Corresponding author : Prof. Martin Vrňata, Tel: +420 22044 3383, email: martin.vrnata@vscht.cz, Department of Physics and Measurements, University of Chemistry and Technology, Technická 5, Prague 6, CZ-166 28, Czech Republic Highlights

The article presents pioneering research of textile chemiresistors on Evolon and Polyester substrates equipped with graphite electrodes and in-situ polymerized poly(tetrabutylphosphonium 3- sulfopropylacrylate) or poly(tributylhexylphosphonium 3-sulfopropylacrylate) sensitive layers. The DC- and AC- responses to $10 \mathrm{ppm}$ of methanol, nitrogen dioxide, 4-bromoacetophenone, diethylmalonate and yperite were then investigated at laboratory temperature - the reference was "pure" synthetic air. Under these circumstances the DC- responses (SDC) varied from 0.48 to 1.36 and maximum AC- responses (Spa) from 8 to $26 \mathrm{deg}$. It was shown that sensor dynamics depends mainly on molecular weight of the analytes. Moreover, the magnitude of AC-responses correlated both qualitatively and quantitatively with the dipole moments of the analyzed molecules.

Keywords: Textile chemiresistors, Polymer ionic liquids, Detection of toxic gases, Discrimination according to dipole moments of analytes 


\section{Introduction}

Application of functional elements and nanostructures on flexible substrates is a promising trend in electronics. Also for fabrication of chemiresistors, there are intensively studied substrates such as plastic foil [1-3], paper [4] and fabric [5-7]; they seem to be a suitable alternative for conventional "hard" alumina substrates equipped with metal electrodes [8]. Textiles are materials with great potential, whose mechanical properties (high strength, large surface area, lightness, flexibility, effortless integration into clothing) make it unique even in comparison with other flexible substrates [9-10]. There are several ways to add new functionalities to textiles when used in sensor applications [8]. The textile substrate can be covered with gas sensitive layer by "wet" and "vacuum" coating techniques, e.g. ink-jet printing [11-12] or magnetron sputtering technology [13]. Other possibilities include the integration of conventional electronics components into a textile substrate by different methods, such as weaving, knitting [5,14], or by using gassensitive nanofibers [15] etc. A common feature of textile sensors is that they operate at either laboratory or at a slightly higher temperature. Therefore organic conductors are preferred to be their sensitive layers.

Polymerized ionic liquids (PILs) have been reported for the first time in 1998, and a brief overview of their properties can be found e.g. in [16]. Their electrotransport properties are unique (when compared with other organic substances), as they are purely ionic conductors. Moreover, majority of them can be considered as single-ion conductors. PILs are characterized by large capacity to absorb analytes with small molecules - especially CO2 and water. When such absorption, the internal volume of polymer is modified, hence the mobility of ions changes [17]. Such a phenomenon could work as a prospective transducer mechanism in chemiresistors. This property of PILs is very valuable, because namely $\mathrm{CO} 2$ and numerous other analytes (whose molecule has neither redox properties, nor dipole moments) cannot be detected on chemiresistors by any other mechanism.

For example, the poly(tetrabutylphosphonium 3-sulfopropylacrylate) used in our research - see below - is composed of the polymeric anion with strictly localized negative charge (i.e. zero charge mobility) and non-polymerized cation, which is responsible for charge transport. The mobility of relatively large cation is strongly influenced by internal free volume of this polymer. Furthermore, another mechanism of modulating the charge mobility in the polymeric matrix is achieved by the rearrangement of the sp3-hybridized tetraalkyl phosphonium to accommodate the analyte gas.

PILs have promising applications as materials for ion selective membranes, in chemical catalysis, for gas storage, in solar cells, supercapacitors, etc. Current state in synthesis and applications of PILs is reviewed in [18]. In the field of sensing, PILs are often employed in electrochemical sensors [19-20], but much rarely for sorbents in QCM sensors [21]. Surprising still, their applications in chemiresistors are at a pioneering stage. In [22] the authors prepared a chemiresistor with the sensitive layer based on a composite of poly[(p-vinylbenzyl)trimethylammonium hexafluorophosphate] and La202CO3 nanoparticles. This chemiresistor exhibited decrease of resistance when exposed to pulses of $\mathrm{CO} 2$ in 50\% relative humidity at room temperature. In [23] the authors report chemiresistor based on three- 
component composite: silver nanoparticles-graphene-poly(ionic liquid). Its DCresponse (SDC) - for definition see Section 2.2 - to $128000 \mathrm{ppm}$ and $1 \mathrm{ppm}$ of methanol achieves 1.53 and 1.03 respectively. However, in this case, PIL is only a minor component of sensitive layer.

Our manuscript presents pioneering research into textile chemiresistors with sensitive layers based on two types of cationic PILs, namely poly(tributylhexylphosphonium 3-sulfopropyl acrylate) - marked as poly(P4,4,4,6SPA) and poly(tetrabutylphosphonium 3-sulfopropylacrylate) - marked as poly(P4,4,4,4SPA)and. It includes: (i) investigation of sensitive layer - electrode contact phenomena by measurement of current voltage-characteristics, (ii) general characterization of the PILs by impedance spectroscopy, (iii) overview and analysis of DC- and ACresponses of PILs sensors to $10 \mathrm{ppm}$ of methanol $(\mathrm{MeOH})$, nitrogen dioxide (NO2), 4-bromoacetophenone (4-BAP), diethylmalonate (DEM) and yperite, (iv) FTIR spectra of PILs exposed- and unexposed- to analyte vapours. Based on these results some general comments and suggestions for future research are proposed.

\section{Experimental section}

\subsection{Fabrication of textile chemiresistors}

This work details the development of a gas sensing chemiresistor using a nonconductive textile (dimensions $10 \times 15 \mathrm{~mm}$ ) as the substrate. The architecture of the sensor can be seen in Fig. 1. Two kinds of textiles of different composition and method of production were used: Evolon - non- woven textile $(70 \%$ polyester $/ 30 \%$ polyamide) was purchased from Polytex Ltd. (Malé Svatoňovice, CZ) and PES woven textile (100\% polyester) was obtained from Kümpers Textil Ltd. (Těchonín, CZ). These textiles were first continuously cleaned in methanol using Soxhlet extraction (10 cycles) then washed with deionized water and finally dried at room temperature. SEM images of the processed textiles are presented in Fig. 2.

In order to improve the mechanical flexibility of the sensor, the thermal adhesive film (Sealon Co., Ltd.) was laminated on the back side of the textile. The film was applied via a Heated Roll Laminator (model Titan-110) under the following conditions: adhesive bonding temperature of $80^{\circ} \mathrm{C}$ for $10 \mathrm{~s}$, at a pressure between 70-140 kPa.

Subsequently, screen printing was used to form the graphitic electrodes on the surface of the textile substrate. The electrodes are in interdigital arrangement and they were printed using a DEK 248 printer (Weymouth, UK) as reported in [24]. Fine line printing graphite paste was used (Gwent Electronic Materials, Pontypool, UK) as a conductive ink. The interdigital electrodes were printed in two different designs, which vary in the distance $(0.5$ or $1.0 \mathrm{~mm}$ respectively - see Fig. 1 right) between them.

The gas sensitive layer is composed of the polymer ionic liquids (PILs). Two kinds of PILs were used in the fabrication process: (i) poly(tributylhexylphosphonium 3sulfopropylacrylate) -the corresponding sensors are labeled as "series A" and (ii) poly(tetrabutylphosphonium 3- sulfopropylacrylate) -the corresponding sensors are labeled as "series B". The list of tested sensors is in Table 1.

The ionic liquid monomers were synthesized by the procedure detailed in [25]. For example $(\mathrm{P} 4,4,4,4 \mathrm{SPA})$ monomer was prepared by mixing tetrabutylphosphonium 
chloride (P4,4,4,4Cl) with $40 \mathrm{ml}$ of deionized water and 1.5 molar equivalents of 3sulfopropylacrylate potassium salt (KSPA). The reaction scheme is depicted in Fig. 3 - top. The reaction mixture was stirred at $30^{\circ} \mathrm{C}$ for $18 \mathrm{~h}$ and subsequently extracted three times with dichloromethane $(25 \mathrm{ml})$. This step was followed by the removal of dichloromethane using a rotary evaporator. The residual solvents were removed using a high vacuum pump (working pressure $0.5 \mathrm{mBar}$ ).

In the next step, the polymerization mixture was prepared, having the following composition: P4,4,4,4SPA monomer, photoinitiator (phenylbis (2,4,6-trimethylbenzoyl) phosphine oxide) and crosslinker (trimethylolpropane ethoxylate triacrylate - TM692) dissolved in the solvent mixture (deionized water with acetonitrile), Table 2 . This mixture was photo-polymerized directly onto the surface of the textile substrate. Firstly, the mixture was drop-cast onto the surface of the textile using a micropipette and subsequently it was polymerized using a LMI-6000 Fiber-Lite white light source ( $200 \mathrm{kLux})$ for $30 \mathrm{~min}$ to create compact sensitive film on textile substrate. The process is schematically depicted in Fig. 3 - bottom. The SEM images of the textile substrates covered with PIL together with several comments are presented in supplementary materials (S1).

\subsection{Instrumentation and analysis}

The surface morphology of the textile sensors was investigated by Field Emission Scanning Electron Microscopy (FESEM), model MIRA LMH (Tescan, CZ). Scanning electron microscope images were obtained using an accelerating voltage of $3 \mathrm{kV}$ at various magnifications. To examine the cross-sections of the PIL coated textile sensors, the samples were cut by Microtome.

SourceMeter Keithley 2410 was used to investigate the current-voltage characteristics of the sensors in pure synthetic air and also in distinct analytes. The applied voltages were in the range from -15 to $+15 \mathrm{~V}$.

In order to study the charge transport properties of sensitive PIL layers, we measured impedance spectra over a wide range of frequencies in pure synthetic air. The impedance spectra were measured on PIL layers equipped with graphite electrodes using a GAMRY Reference 600 impedance analyzer in the range of frequencies from $10 \mathrm{mHz}$ to $1 \mathrm{MHz}$. The results were printed as Nyquist plots. Current-voltage characteristics and impedance spectra served as basic tools for investigating the electrical properties of the sensor and its components, therefore their measurement was performed under "reference" conditions, i.e. in synthetic air at $22^{\circ} \mathrm{C}$.

The gas sensing properties were evaluated in both DC- and AC- operation mode. The principal configuration of the apparatuses for both measurements is identical (Fig. 4). They are constructed as continuous-flow systems. Their gas-distribution system includes: two Tedlar bags for the reference and the tested mixture, respectively; two solenoid switching valves; glass pipes and a teflon measuring chamber with the textile sensor. The constant flow rate of $40 \mathrm{ml} \cdot \mathrm{min}-1$ is controlled by the rotameter (Aalborg Instruments \& Controls, model P $150 \mathrm{ml}$ ).The dead volume of the apparatus including its part from the solenoid switching valves to rotameter is $\sim 20$ $\mathrm{ml}$. All the DC- and AC-measurements were made at the constant temperature of $22^{\circ} \mathrm{C}$. The reference atmosphere was synthetic air, while the measured analytes (nitrogen dioxide, methanol, 4-bromacetophenone, diethylmalonate, yperite) were 
diluted to a concentration of $10 \mathrm{ppm}$ by synthetic air. When studying the response in DC-mode, the "central" measuring device used was an Agilent 34410A digital multimeter in 2-wire connection, while in AC-mode we used Agilent 4294A impedance analyzer in 4-wire connection, with the frequency range set between 40 $\mathrm{Hz}$ and $10 \mathrm{MHz}$. Before each measuring cycle the sensor was firstly left for 10 minutes in the presence of synthetic air in order to stabilize the electrical parameters of the sensitive layer. Following this, the measurement cycle was initiated. This consisted of 10 minutes in synthetic air, followed by 10 minutes in the analyte. This cycle was repeated three times. The DC- response to yperite was studied separately at the University of Defence (Vyškov, Czech Republic) with an Agilent 34410A digital multimeter in 2-wire connection, but the continuous-flow apparatus for these experiments was different than the one used for the other measurements. For this reason, in the case of yperite only DC-response is presented (Table 3 and Fig. 8).

The sensor DC-response, i.e. SDC, was calculated according to the formula: SDC=Rair/Rgas, where Rair is the steady state resistance value in synthetic air and Rgas is the analogous value in the atmosphere containing $10 \mathrm{ppm}$ of detected gas. From DC-measurements also dynamic parameters (response time and recovery time) of sensors were calculated. Response time ( $\tau 90)$ is recorded as the timespan necessary to achieve $90 \%$ of the difference of sensor resistance from Rair (steady state value) to Rgas (steady state value) after the switching of atmosphere: "pure" synthetic air $\rightarrow$ synthetic air containing $10 \mathrm{ppm}$ of analyte. Recovery time $\left(\tau^{*} 90\right)$ is an analogous parameter for the opposite change: synthetic air containing $10 \mathrm{ppm}$ of analyte $\rightarrow$ "pure" synthetic air. For evaluation of the AC-response of sensors, we measured their Nyquist plots and subsequently calculated the so called phase-angle sensitivity Spa as described in [26].

To study the detection mechanism, FTIR spectra of poly(P4,4,4,4SPA) were taken in synthetic air and in synthetic air containing saturated vapors of analytes respectively. Thin films of the PIL were deposited on silicon substrates by analogous procedure described above. The spectra were taken using a Nicolet iS5 in transmission mode (resolution $4 \mathrm{~cm}-1$ ). Firstly, the spectrum of a thin film of PIL on silicon substrate was measured in synthetic air; secondly the sample was exposed to saturated vapor of the respective analyte for 1 hour (outside the spectrometer device); thirdly, the as-exposed sample was turned back to spectrometer and measured immediately. In all cases, the background represented by signal recorded from uncovered silicon substrates measured in synthetic air was subtracted.

\section{Results and discussion}

\subsection{Current-voltage characteristics of the sensor}

When considering the chemiresistor as an electronic device, with respect to the flow of measuring current, one can take the view that there are two electrode-sensitive layer junctions in an anti-series arrangement. To understand sensor functionality, it is necessary to inspect the behaviour of these junctions in terms of current-voltage characteristics. Fig. 5 displays the data obtained with sensor A1 in the range of voltage from $-15 \mathrm{~V}$ to $+15 \mathrm{~V}$. It is apparent that the $\mathrm{V}$-I characteristics are linear, without any rectifying effect. Their general character is independent of the composition of the surrounding atmosphere. Hence the contacts are classified as 
Ohmic and thus the processes taking place at electrode-sensitive layer junction should play only a negligible role when measuring and evaluating the DC-response of the sensor. Similar V-I characteristics were obtained for other sensors in this study. Moreover, there weren't any changes found in the slope (k) of the V-I characteristics even after repeated (10 times) mechanical bending of the sensors, which simulates real conditions of the sensor when integrated into a device as a smart-textile.

Our observations are in accordance with [27], where the authors state that of the electrode materials (noble metals, conductive polymers, graphite) commonly used for contacting organic materials, graphite would be the best choice. The suitability of the graphite stems primarily from the value of its work function (graphite: $\Phi=$ $4.8 \mathrm{eV}$; aluminium: $\Phi=4.2 \mathrm{eV}$; gold: $\Phi=5.3 \mathrm{eV}$; platinum: $\Phi=5.9 \mathrm{eV}$ ), which lies just between the typical values of ionization potential of organic electron donors (ID $\sim 7.0 \mathrm{eV}$ ) and the typical values of electron affinity of organic electron acceptors (ID $\sim 3.0 \mathrm{eV}$ ); such circumstance minimizes the probability of Schottky behavior when contacting majority of organic materials. Graphite also exhibits chemical inertness, at laboratory temperature it does not react with any corrosive gas detected by the sensor and, last but not least, graphite paste has a much better cohesion and mechanical flexibility together with the textile substrate when compared with evaporated or sputtered metal contacts.

3.2 Impedance spectra of sensitive layers based on PILS

Both the Nyquist plots depicted in Fig. 6 (sensors A2 and B4) have a common character: depressed semicircles with a low-frequency tail. The occurrence of the tail suggests a strong influence from ionic conductivity at low frequencies [28]. In terms of equivalent circuit parameters such behaviour can be modelled by a parallel combination of a resistor and a generalized capacitor - Constant Phase Element (CPE). Two remarks need to be made with regards to the Nyquist plots: a) When measuring from such low frequency as $10 \mathrm{mHz}$ i.e. "in quasi dc-mode", the character of Nyquist plot is rather different than that measured from $40 \mathrm{~Hz}$ (discussed in the comments of Fig. 9), and b) The processes observed in "quasi dc-mode" are too slow to be applicable in sensors operating in real-time conditions.

Nevertheless, they are very important for understanding charge transport mechanisms in PILs and they will become a subject of future studies.

Reports concerning the impedance spectroscopy of polymer ionic liquids are still rare. In [29] the authors measured a PIL of different composition in the frequency range $1 \mathrm{~Hz}-10 \mathrm{MHz}$ and obtained the same character of Nyquist plot as presented in Fig. 6. In contrast, in [30] only the tail was observed in the Nyquist plot (frequency range $1 \mathrm{~Hz}-1 \mathrm{MHz}$ ). The tail without the preceding semicircle would suggest a series combination of a capacitor and a CPE.

3.3 DC-responses to toxic gases and chemical warfare agent

Selection of tested sensors: The overview of measured sensors is detailed in Table 1. In the case of the chemiresistor substrate, either non-woven Evolon or woven PES (Fig. 2) was selected. The distance between the graphite electrodes was 0.5 or 1.0 $\mathrm{mm}$, respectively. The active layer was composed of poly(P4,4,4,6SPA) in the case of the A sensor series, or poly $(\mathrm{P} 4,4,4,4 \mathrm{SPA})$ in the case of the B sensor series. Selection of tested analytes: The tested analytes were: methanol, nitrogen dioxide, 4- 
bromoacetophenone and diethylmalonate, all in $10 \mathrm{ppm}$ concentration, and the reference gas was synthetic air. Each analyte was selected as the representative of certain class of substances - methanol behaves as a reducing agent, nitrogen dioxide is a strong oxidizing agent, 4-bromoacetophenone possesses a halogen heteroatom (as do the majority of chemical warfare agents) and diethylmalonate has been reported as a substance similar to Yperite with the so-called Tanimoto coefficient (TC) of similarity equal to 0.167 . The TC of given substance is calculated on the basis of molecular descriptors as a real value from the interval between 0 and 1; the higher the value is, the more similar is the substance to a real chemical warfare agent [31]. Table 3 provides an overview of DC-responses for the whole set of experiments, Table 4 summarizes the dynamic parameters and baseline of the sensors, Fig. 7 depicts the time-dependent resistance of A1 sensor in various analytes and Fig. 8 shows the time-dependent resistance of A4 sensor in yperite. Finally, Fig. 9 depicts the response of sensor A1 to concentration scale of 100 ppb, 1 ppm, $10 \mathrm{ppm}$ and $100 \mathrm{ppm}$ methanol.

DC-responses: Both methanol and 4-BAP always show decreased sensor resistance. The decrease in sensor resistance in the presence of polar molecules such as 4-BAP and $\mathrm{MeOH}$ can be explained as follows: These molecules readily solvate the poly(SPA) chains thus causing an increased mobility of the phosphonium cations $(\mathrm{P} 4,4,4,4$ and $\mathrm{P} 4,4,4,6)$. On the contrary, NO2 always increased the sensor resistance. The response of the sensors to DEM was surprising, as sensor resistance for all sensors of A series increased, but, conversely, it decreased for all sensors of B series. This would suggest a different spatial rearrangement of the sp3-hybridized $\mathrm{P} 4,4,4,4$ cation in comparison to $\mathrm{P} 4,4,4,6$ in the presence of DEM analyte gas, leading to different degree of mobility of the tetraalkyl phosphonium cation. Of all sensors, the most pronounced responses to all analytes were recorded on $\mathrm{A} 1$ and $\mathrm{B} 2$. Furthermore, B4 sensor can be regarded as selective to NO2. When averaging the SDC values achieved on corresponding sensors with the same distance between graphitic electrodes (i.e. A1+A2, A3+A4, B1+B2, B3+B4 respectively), one can see that for lower distance of electrodes the SDC values are somewhat higher, i.e. $A 1+A 2$ exhibit higher SDC values than A3+A4, etc. The response of A4 sensor to yperite is rather high - in an absolute value this is the second highest response of all the cases when the sensor resistance decreases in the presence of the analyte. The only "comparison" of our results with chemiresistors based on PILs can be made with those published in [22], where the sensors exhibit SDC $=1.03$ at $150 \mathrm{ppm}$ of $\mathrm{CO2}$.

The values of SDC obtained in the case of the A1 and A2 sensors for distinct analytes (Table 3) should exhibit a positive correlation with the slope $\mathrm{k}$ of the V-I characteristics measured in respective analytes (Fig. 5). In fact, for the SDC values we observed the relation $\mathrm{MeOH}>4-\mathrm{BAP}>$ synthetic air $>\mathrm{DEM}>\mathrm{NO} 2$ and for the $\mathrm{k}$ values the relation was $\mathrm{DEM}>\mathrm{MeOH}>4-\mathrm{BAP}>$ synthetic air $>\mathrm{NO} 2$. It is apparent that the only discrepancy was found for DEM. At present we cannot explain the reason for this behaviour.

Dynamic parameters and baseline values: As for the dynamic parameters, we must take into account that - in fact - we determined the dynamic parameters of not only the sensor itself, but of the whole testing apparatus (which had approx. 2 min dead time - see Experimental section). Furthermore, the result $\tau 90>10$ min or $\tau^{*} 90>10$ 
min does not mean that a given sensor is not applicable for practical use. When comparing the response time of each analyte, the fastest response- and recoverytime was recorded for NO2 and, conversely, the slowest dynamics was observed for DEM. It suggests that the $\tau 90$ and $\tau * 90$ values are to a certain extent correlated with molecular weight of the tested analyte $\mathrm{M}(\mathrm{MeOH})=32$ g.mol-1, $\mathrm{M}(\mathrm{NO} 2)=46$ g.mol-1, $\mathrm{M}(4-\mathrm{BAP})=199$ g.mol-1, $\mathrm{M}(\mathrm{DEM})=160$ g.mol-1, i.e. analytes with large molecules exhibit slower dynamics. Another factor which could cause the slow response to DEM is that this molecule has two relatively reactive ester groups; hence it behaves like a "bi-dental" gas species. Except for a few cases, the recovery time is longer than the response one, which is typical behaviour for chemiresistors [32]. For yperite the $\tau 90$ and $\tau^{* 90}$ values were not calculated, as this analyte was measured in a completely different apparatus (non-flow system) and hence the dynamic data gathered are not comparable.

The value of the baseline for the presented set of sensors has a range between 2.4 and 11.2 $\mathrm{M} \Omega$. The sensors from series "B" have better stability of their baseline than the sensors from series "A". Moreover, it is important to point out that in the case of sensor A1, which exhibits a relatively unstable baseline, the high value of its SDC is maintained. The sensor reported at [22] has Rair $\approx 1.7 \mathrm{G} \Omega$, i.e. 2-3 orders higher than our samples. Such high baseline brings numerous troubles in practical measurement.

As for dependence of sensor response on concentration of the analyte, an example is given on Fig. 9, which illustrates detection of $\mathrm{MeOH}$ on sensor $\mathrm{A} 1$. What is apparent: (i) the sensor baseline (Rair) slightly drifts to lower values; (ii) an average value of SDC achieves 1.05 for $100 \mathrm{ppb}, 1.25$ for $1 \mathrm{ppm}, 1.29$ for $10 \mathrm{ppm}$ and 1.39 for 100 ppm of MeOH respectively; (iii) the sensor output signal exhibits a very low level of noise, hence as low concentration as $100 \mathrm{ppb}$ of $\mathrm{MeOH}$ is above the detection limit. Unfortunately, we did not find references to compare our results with those obtained by other research groups.

3.4 AC-responses to toxic gases

The AC-responses of textile sensors to toxic gases were plotted as Nyquist plots. An illustrative example is provided in Fig. 10, in which the characteristics of sensor B3 are presented. The results indicate the following: (i) the shape of Nyquist plots in distinct analytes remains uniform, i.e. one dominating semi-circle; (ii) when comparing these plots with Fig. 6, which was measured in synthetic air starting from significantly lower frequency $(10 \mathrm{mHz})$, it is apparent that some curves in Fig. 10 contain a rudimental "tail" of ionic conductivity towards the right side; (iii) the absolute values of complex impedance measured at $40 \mathrm{~Hz}$ correlate with SDC values - presented in Table 3 for sensor B3 - i.e. nitrogen dioxide is the only analyte, for which the sensor impedance increases.

One of the possibilities for extracting an easily processable signal from the Nyquist plots is to evaluate the phase-angle sensitivity Spa as mentioned in Section 2.2. The results are depicted in Fig. 11. When considering the influence of the analytes to the values of Spa, we can state that 4-BAP exhibited the highest values (22 deg. and 26 deg. respectively); $\mathrm{MeOH}$ the second highest ones (12 deg. and $13 \mathrm{deg}$.); followed by DEM (14 deg. and 8 deg.); and finally, NO2 exhibited the lowest ones (8 deg. and 7 deg. respectively). This sequence quantitatively correlates with dipole moments $(\mu)$ 
of analyte molecules: 4-BAP $\mu=3.1$ Debye; $\mathrm{MeOH} \mu=1.7$ Debye; DEM $\mu=1.5$ Debye; N02 $\mu=0.6$ Debye. Thus phase-angle sensitivity can become a criterion for discriminating the analytes according to the dipole moment of their molecules.

It is known that in chemiresistors the frequency of the Spa maximum (fmax) is primarily given by the material of the sensitive layer. For sensors based on PILs, the values for the Spa maxima are observed within a relatively narrow range of fmax = $(1-4) \times 104 \mathrm{~Hz}$ (see Fig. 11). In previous research our group investigated other classes of sensitive layer materials with fmax as follows: tin dioxide with fmax $=7 \mathrm{x}$ $105 \mathrm{~Hz}$ [26]; acetylacetonates with fmax $=4 \mathrm{x} 105 \mathrm{~Hz}$, polypyrrole with fmax $=5 \mathrm{x}$ $103 \mathrm{~Hz}$ [28] and sulphonated phthalocyanines fmax = 5 x $105 \mathrm{~Hz}$ [33].

3.5 Changes in FTIR spectra on exposure to analytes

Diethylmalonate (DEM) was the only analyte, whose presence in PIL was detectable by FTIR spectroscopy. The reason behind this behaviour is probably connected to the above mentioned fact that DEM behaves like "bi-dental" species as discussed in Section 3.3 and hence it has better cohesion to PILs compared with other analytes. Furthermore, the absorption of DEM vapors by the PIL sensitive layer was found to be a fully reversible process even at laboratory temperature. On exposure to pure synthetic air all the peaks attributed to DEM disappeared completely from the FTIR spectra. The spectra of PIL in synthetic air, DEM vapors, and PIL exposed to DEM vapors are presented in Fig. 12.

FTIR spectra: The FTIR spectrum of PIL in air contains the characteristic peaks (Table 5) specific to C-H stretching (2958 cm-1), -C=0 stretching (1718 cm-1), S=0 stretch (1190 cm-1), C-O-C bond stretching vibration $(1095 \mathrm{~cm}-1)$ and P-C stretching vibrations $(1464 \mathrm{~cm}-1,724 \mathrm{~cm}-1)$. A new $-\mathrm{C}=0$ peak appears in the case of PIL in the presence of diethylmalonate, at $1752 \mathrm{~cm}-1$ characteristic for diethylmalonate [34,35]. Two other DEM signature peaks are visible at 1370 and $1333 \mathrm{~cm}-1$ (extra refs: [36,37]).

\section{Conclusions}

We prepared two series of textile chemiresistors on Evolon and PES substrates equipped with graphite electrodes and in-situ polymerized poly(P4,4,4,6SPA) or poly(P4,4,4,6SPA) sensitive layers. Electrical characteristics of the prepared sensors, the magnitude and the dynamics of their DC- and AC- responses at laboratory temperature when exposed to toxic gases (nitrogen dioxide, methanol, 4bromacetophenone, diethylmalonate) were investigated.

The graphite electrodes proved their suitability for textile sensors, as the contact graphite-PIL is non- rectifying. Moreover, the V-I characteristics of sensor assembly exhibit long-term stability together with stability towards mechanical bending. The equivalent circuit of the sensor assembly contains a combination of a resistor and a Constant Phase Element connected in parallel.

In case of the DC-responses of the reported sensors, it is remarkable that when exposed to strongly oxidizing (nitrogen dioxide, SDC $<1$ ) and strongly reducing (methanol SDC $>1$ ) analyte, the sensitive layer behaves like n-type semiconductor, irrespective of its ionic conductivity. The occurrence of such phenomenon also indicates that "simple" modulation of ionic conductivity by molecules of analyte entrapped in internal volume of the PIL cannot be considered as the only detection mechanism. Nevertheless, investigation of detection mechanisms in chemiresistors 
based on PILs would be a worthy subject of research in the future. The highest DCresponses were as follows: sensor A1 (Evolon / poly(P4,4,4,6SPA) with a distance of $0.5 \mathrm{~mm}$ between electrodes) achieved $\mathrm{SDC}=1.37$ when detecting 4-BAP and sensor B4 (PES / poly(P4,4,4,4SPA) with a distance of $1.0 \mathrm{~mm}$ between) SDC $=0.48$ when detecting NO2. Further, such low concentration as $100 \mathrm{ppb}$ of $\mathrm{MeOH}$ is detectable on sensor A1 (SDC = 1.03). With respect to low level of noise of output sensor signal, $100 \mathrm{ppb}$ of $\mathrm{MeOH}$ is above the detection limit.

It was proved that the sensor dynamics (i.e. response and recovery time) are influenced by the molecular weight of the analyte and also by the number of reactive centers in its molecule. From a practical point of view, the sensors are applicable for real-time alarms, as a sudden change in their resistance occurs in tens of seconds after a change in its surrounding atmosphere takes place.

The AC-responses were presented in the form of Nyquist plots, together with the values of phase- angle sensitivity Spa. We found that the value of Spa correlates both qualitatively and quantitatively with dipole moment of the analyte. So, there is a prospective tool for discrimination of analytes according to their dipole moment.

The research of textile chemiresistors with active layers based on PILs is in its initial stage, but this class of sensors is worthy of further research.

\section{Acknowledgements}

This work was supported by Czech Science Foundation (GACR), Project No. 1713427S, by NATO's Public Diplomacy Division in the framework of “Science for Peace" programme, project No.984597 and also by Ministry of Education, Youth and Sports in frame of project LTC17058 and by COST Action CA15107 MultiComp. Financial support from specific university research (MSMT No 20- SVV/2017) is also acknowledged. Alexandru Tudor, Larisa Florea and Dermot Diamond are grateful for financial support from the Marie Curie Initial Training Network funded by the EC FP7 People Programme OrgBIO (Marie Curie ITN, GA607896) and Science Foundation Ireland (SFI) under the Insight Centre for Data Analytics initiative, Grant Number SFI/12/RC/2289.

Source material of phosphonium salt was provided with courtesy by CYTEC Ltd.

\section{References}

[1] A. Oprea, J. Courbat, D. Briand, N. Bârsan, U. Weimar, N.F. de Rooij, Environmental monitoring with a multisensor platform on polyimide foil, Sensors Actuators B Chem. 171 (2012) 190-197. doi:https://doi.org/10.1016/j.snb.2012.02.095.

[2] C. Ataman, T. Kinkeldei, A. Vasquez-Quintero, F. Molina-Lopez, J. Courbat, K. Cherenack, D. Briand, G. Tröster, N.F. de Rooij, Humidity and Temperature Sensors on Plastic Foil for Textile Integration, Procedia Eng. 25 (2011) 136-139. doi:https://doi.org/10.1016/j.proeng.2011.12.034.

[3] E. Skotadis, D. Mousadakos, K. Katsabrokou, S. Stathopoulos, D. Tsoukalas, Flexible polyimide chemical sensors using platinum nanoparticles, Sensors Actuators B Chem. 189 (2013) 106-112. doi:https://doi.org/10.1016/j.snb.2013.01.046.

[4] A. Arena, N. Donato, G. Saitta, A. Bonavita, G. Rizzo, G. Neri, Flexible ethanol sensors on glossy paper substrates operating at room temperature, Sensors Actuators B Chem. 145 (2010) 488-494. 
doi:https://doi.org/10.1016/j.snb.2009.12.053.

[5] C. Ataman, T. Kinkeldei, G. Mattana, A. Vásquez Quintero, F. Molina-Lopez, J. Courbat, K. Cherenack, D. Briand, G. Tröster, N.F. de Rooij, A robust platform for textile integrated gas sensors, Sensors Actuators B Chem. 177 (2013) 1053-1061. doi:https://doi.org/10.1016/j.snb.2012.11.099.

[6] G.E. Collins, L.J. Buckley, Conductive polymer-coated fabrics for chemical sensing, Synth. Met. 78 (1996) 93-101. doi:https://doi.org/10.1016/03796779(96)80108-1.

[7] R. Wang, J.H. Xin, X.M. Tao, W.A. Daoud, ZnO Nanorods grown on cotton fabrics at low temperature, Chem. Phys. Lett. 398 (2004) 250-255.

doi:https://doi.org/10.1016/j.cplett.2004.09.077.

[8] L.M.C. and A.B. Flatau, Smart fabric sensors and e-textile technologies: a review, Smart Mater. Struct. 23 (2014) 53001.

http://stacks.iop.org/0964-1726/23/i=5/a=053001.

[9] D. Kincal, A. Kumar, A.D. Child, J.R. Reynolds, Conductivity switching in polypyrrole-coated textile fabrics as gas sensors, Synth. Met. 92 (1998) 53-56. doi:https://doi.org/10.1016/S0379- 6779(98)80022-2.

[10] T. Ghosh, A. Dhawan, Electronic textiles and their potential, Indian J. Fibre Text. Res. 31 (2006) 170-176.

[11] J. Weremczuk, G. Tarapata, R. Jachowicz, Humidity Sensor Printed on Textile with Use of Ink-Jet Technology, Procedia Eng. 47 (2012) 1366-1369.

doi:https://doi.org/10.1016/j.proeng.2012.09.410.

[12] K. Crowley, A. Morrin, A. Hernandez, E. O'Malley, P.G. Whitten, G.G. Wallace, M.R. Smyth, A.J. Killard, Fabrication of an ammonia gas sensor using inkjet-printed polyaniline nanoparticles, Talanta. 77 (2008) 710-717.

doi:https://doi.org/10.1016/j.talanta.2008.07.022.

[13] Z.H. Lim, Z.X. Chia, M. Kevin, A.S.W. Wong, G.W. Ho, A facile approach towards $\mathrm{ZnO}$ nanorods conductive textile for room temperature multifunctional sensors, Sensors Actuators B Chem. 151 (2010) 121-126.

doi:https://doi.org/10.1016/j.snb.2010.09.037.

[14] C. Zysset, N. Nasseri, L. Büthe, N. Münzenrieder, T. Kinkeldei, L. Petti, S. Kleiser, G.A. Salvatore, M. Wolf, G. Tröster, Textile integrated sensors and actuators for nearinfrared spectroscopy, Opt. Express. 21 (2013) 3213-3224.

doi:10.1364/OE.21.003213.

[15] K. Cherenack, L. van Pieterson, Smart textiles: Challenges and opportunities, J. Appl. Phys. 112 (2012) 91301. doi:10.1063/1.4742728.

[16] N. Nishimura, H. Ohno, 15th anniversary of polymerised ionic liquids, Polymer (Guildf). 55 (2014) 3289-3297.

doi:https://doi.org/10.1016/j.polymer.2014.02.042.

[17] J. Yuan, D. Mecerreyes, M. Antonietti, Poly(ionic liquid)s: An update, Prog. Polym. Sci. 38 (2013) 1009-1036.

doi:https://doi.org/10.1016/j.progpolymsci.2013.04.002.

[18] W. Qian, J. Texter, F. Yan, Frontiers in poly(ionic liquid)s: syntheses and applications, Chem. Soc. Rev. 46 (2017) 1124-1159. doi:10.1039/C6CS00620E.

[19] D. Wei, A. Ivaska, Applications of ionic liquids in electrochemical sensors, Anal. Chim. Acta. 607 (2008) 126-135. doi:https://doi.org/10.1016/j.aca.2007.12.011. 
[20] P. Kuberský, J. Altšmíd, A. Hamáček, S. Nešpůrek, O. Zmeškal, An electrochemical NO2 sensor based on ionic liquid: Influence of the morphology of the polymer electrolyte on sensor sensitivity, Sensors. 15 (2015) 28421-28434. doi:10.3390/s151128421.

[21] X. Jin, L. Yu, D. Garcia, R.X. Ren, X. Zeng, Ionic Liquid High-Temperature Gas Sensor Array, Anal. Chem. 78 (2006) 6980-6989. doi:10.1021/ac0608669.

[22] C. Willa, J. Yuan, M. Niederberger, D. Koziej, When Nanoparticles Meet Poly(Ionic Liquid)s: Chemoresistive CO2 Sensing at Room Temperature, Adv. Funct. Mater. 25 (2015) 2537-2542. doi:10.1002/adfm.201500314.

[23] T.T. Tung, M. Castro, T.Y. Kim, K.S. Suh, J.F. Feller, High stability silver nanoparticles- graphene/poly(ionic liquid)-based chemoresistive sensors for volatile organic compounds' detection Chemosensors and Chemoreception, Anal. Bioanal. Chem. 406 (2014) 3995-4004. doi:10.1007/s00216-013-7557-y.

[24] C. Zuliani, G. Matzeu, D. Diamond, A potentiometric disposable sensor strip for measuring $\mathrm{pH}$ in saliva, Electrochim. Acta. 132 (2014) 292-296. doi:https://doi.org/10.1016/j.electacta.2014.03.140.

[25] A. Tudor, L. Florea, S. Gallagher, J. Burns, D. Diamond, Poly(Ionic Liquid) SemiInterpenetrating Network Multi-Responsive Hydrogels, Sensors. 16 (2016) 219. doi:10.3390/s16020219.

[26] V. Myslıḱk , F. Vysloužil, M. Vrňata, Z. Rozehnal, M. Jelıń ek, R. Fryček, M. Kovanda, Phase ac-sensitivity of oxidic and acetylacetonic gas sensors, Sensors Actuators B Chem. 89 (2003) 205-211. doi:https://doi.org/10.1016/S09254005(02)00466-5.

[27] R. Metzger, Unimolecular Electronics, in: Nano Mol. Electron. Handb., CRC Press, 2007: pp. 3-25. doi:doi:10.1201/9781420008142.ch3.

[28] M. Vrňata, D. Kopecký, F. Vysloužil, V. Myslík, P. Fitl, O. Ekrt, J. Hofmann, L. Kučera, Impedance properties of polypyrrolic sensors prepared by MAPLE technology, Sensors Actuators B Chem. 137 (2009) 88-93.

doi:https://doi.org/10.1016/j.snb.2008.11.013.

[29] R. Vera, L. Gelde, E. Anticó, M. V Martínez de Yuso, J. Benavente, C. Fontàs, Tuning physicochemical, electrochemical and transport characteristics of polymer inclusion membrane by varying the counter-anion of the ionic liquid Aliquat 336, J. Memb. Sci. 529 (2017) 87-94. doi:https://doi.org/10.1016/j.memsci.2017.01.055. [30] R. Aranowski, I. Cichowska-Kopczyńska, B. Dębski, P. Jasiński, Conductivity and viscosity changes of imidazolium ionic liquids induced by $\mathrm{H} 2 \mathrm{O}$ and CO2, J. Mol. Liq. 221 (2016) 541- 546. doi:https://doi.org/10.1016/j.molliq.2016.06.010.

[31] J. Lavoie, S. Srinivasan, R. Nagarajan, Using cheminformatics to find simulants for chemical warfare agents, J. Hazard. Mater. 194 (2011) 85-91. doi:https://doi.org/10.1016/j.jhazmat.2011.07.077.

[32] M. Babaei, N. Alizadeh, Methanol selective gas sensor based on nano-structured conducting polypyrrole prepared by electrochemically on interdigital electrodes for biodiesel analysis, Sensors Actuators B Chem. 183 (2013) 617-626. doi:https://doi.org/10.1016/j.snb.2013.04.045.

[33] P. Fitl, M. Vrnata, D. Kopecky, J. Vlcek, J. Skodova, J. Bulir, M. Novotny, P. Pokorny, Laser deposition of sulfonated phthalocyanines for gas sensors, Appl. Surf. Sci. 302 (2014) 37-41. doi:https://doi.org/10.1016/j.apsusc.2014.01.128. 
[34] M.L. Bender, J. Figueras, The Infrared Spectra of Enolate Ions, J. Am. Chem. Soc. 75 (1953) 6304. doi:10.1021/ja01120a505.

[35] R.A. Abramovitch, the Infrared Spectra of Malonate Esters, Can. J. Chem. 36 (1958) 151-158. doi:10.1139/v58-019.

[36] Coblentz Society; Inc., Evaluated Infrared Reference Spectra, in: NIST Chem. WebBook, NIST Stand. Ref. Database Number 69, 2011. doi:10.18434/T4D303.

[37] Nippon paint Co.,Ltd. Method for preparing malonate group-containing acrylate monomers. Inventors: T. Irie et.al. Int. Cl. C07C 69/34. United States Patent, 6054 606.2000-4_25.

[38] M.T. Rahman, Z. Barikbin, A.Z.M. Badruddoza, P.S. Doyle, S.A. Khan, Monodisperse polymeric ionic liquid microgel beads with multiple chemically switchable functionalities, Langmuir. 29 (2013) 9535-9543.

doi:10.1021/la401613w.

[39] CMiB, [2-(Methacryloyloxy)ethyl]dimethyl-(3-sulfopropyl)ammonium hydroxide IR Spectrum, (2011). doi:10.20922/CMIB.10911.

[40] N.A. Meredith, J. Volckens, C.S. Henry, Paper-based microfluidics for experimental design: screening masking agents for simultaneous determination of Mn(II) and Co(II), Anal. Methods. 9 (2017) 534-540. doi:10.1039/C6AY02798A. 

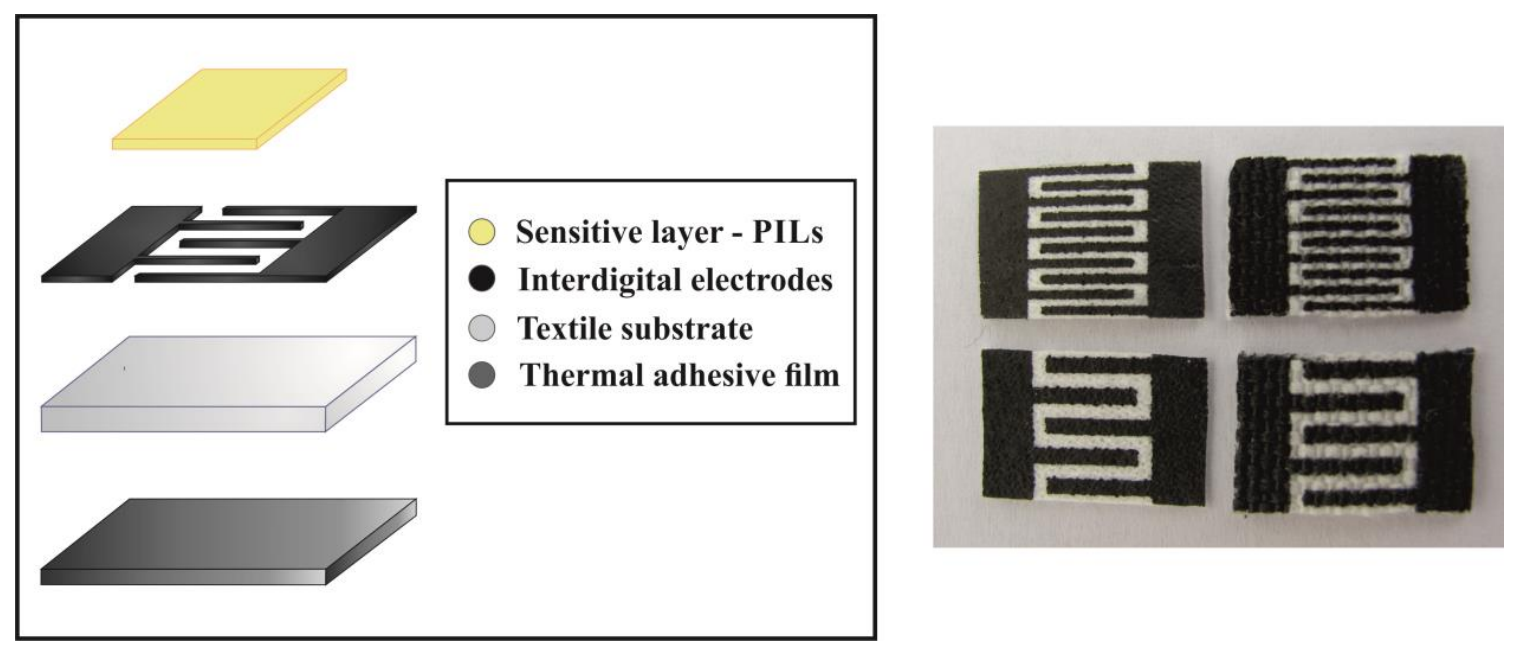

Fig. 1. Vertical architecture of the textile-based sensor (left) and its real appearance indicating variable distances between the electrodes (right).

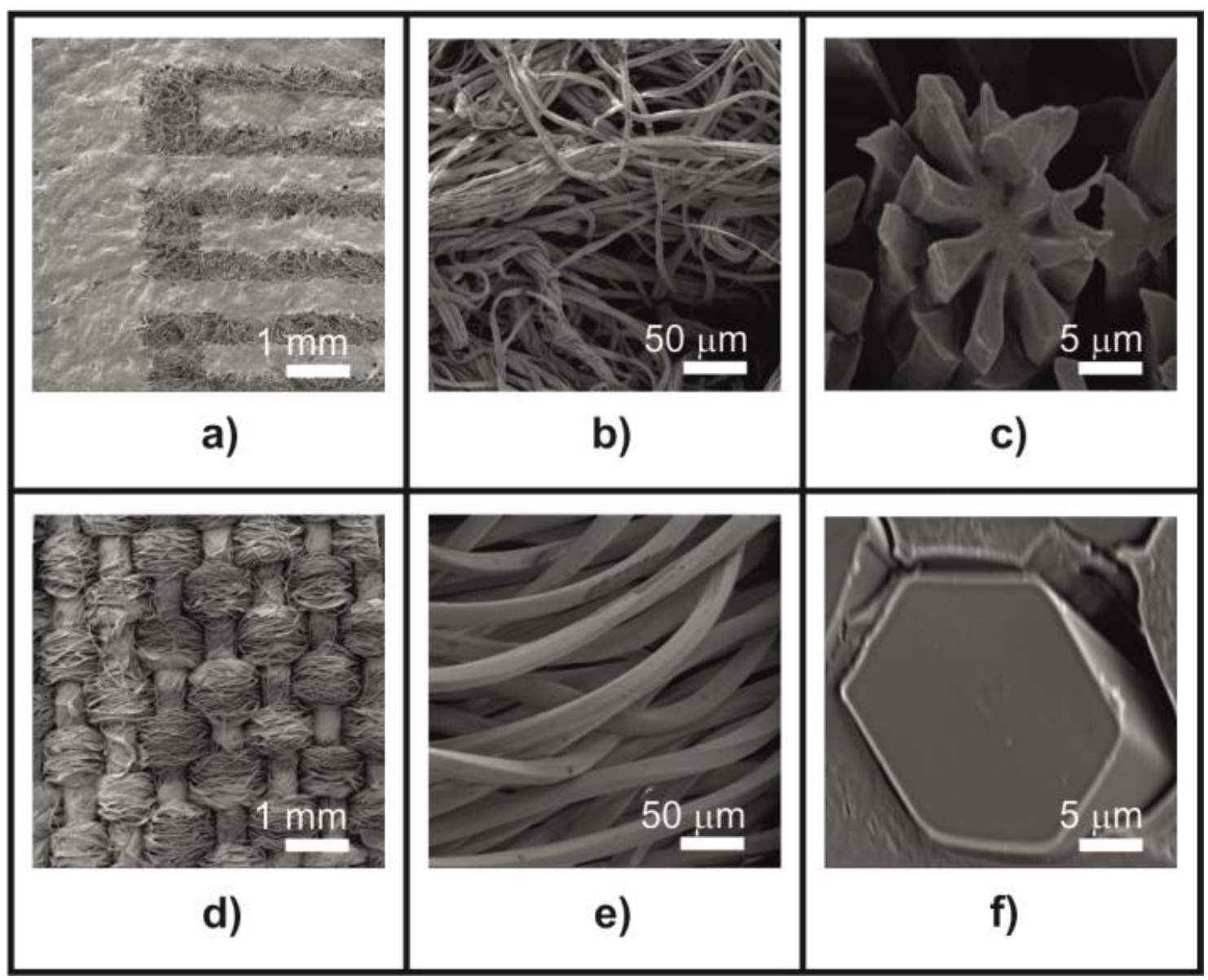

Fig. 2. Variably scaled SEM images of textile substrates for chemiresistors: a) Evolon - with graphitic electrodes; b) Evolon - detail of non-woven textile; c) Evolon cross section of individual fiber; d) PES - with graphitic electrodes; e) PES - detail of woven textile; f) PES - cross section of individual fiber. 

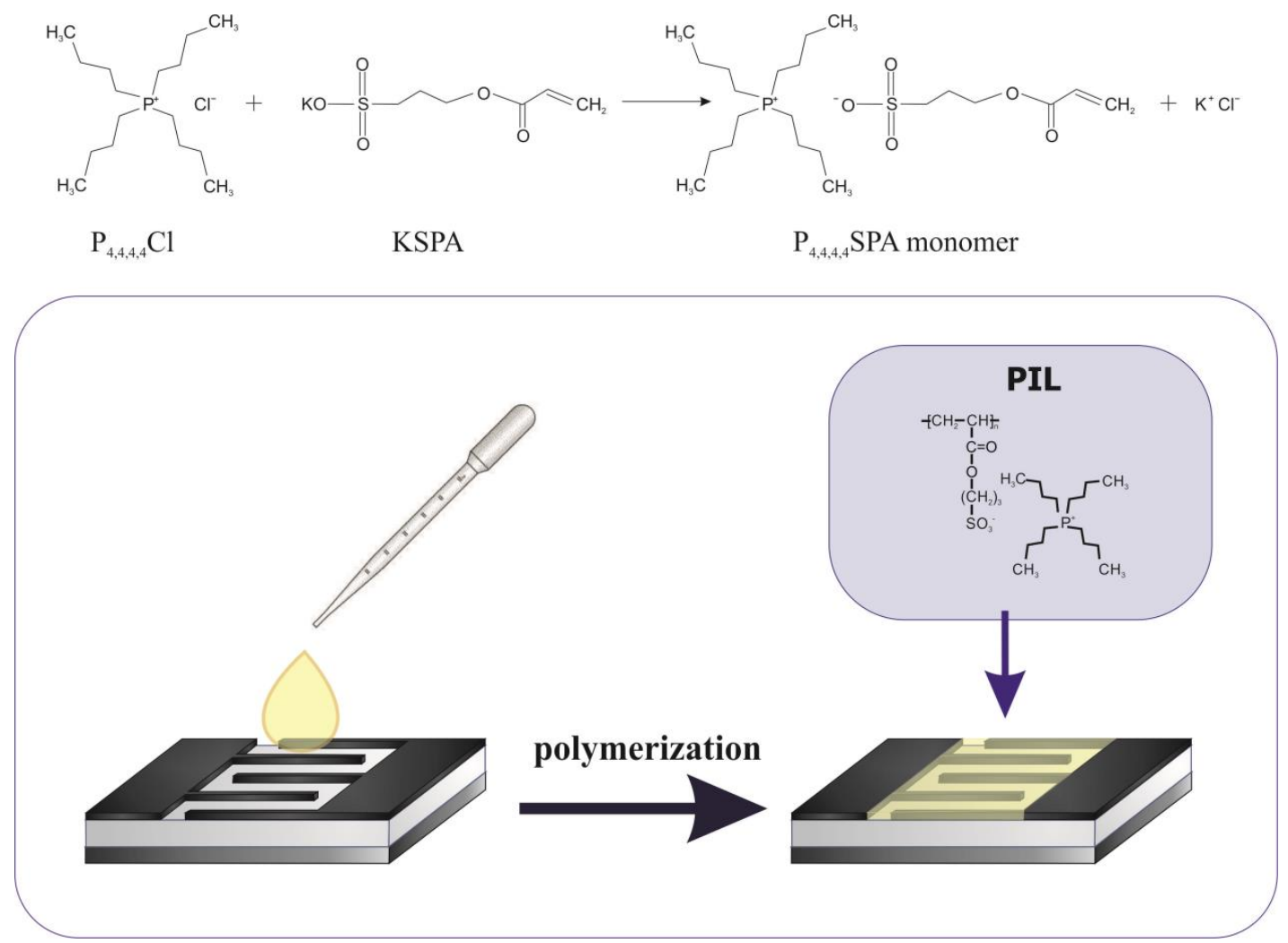

Fig. 3. The synthesis of $(\mathrm{P} 4,4,4,4 \mathrm{SPA})$ monomer by reaction in aqueous solution top; deposition of sensitive layer on textile substrate - bottom.

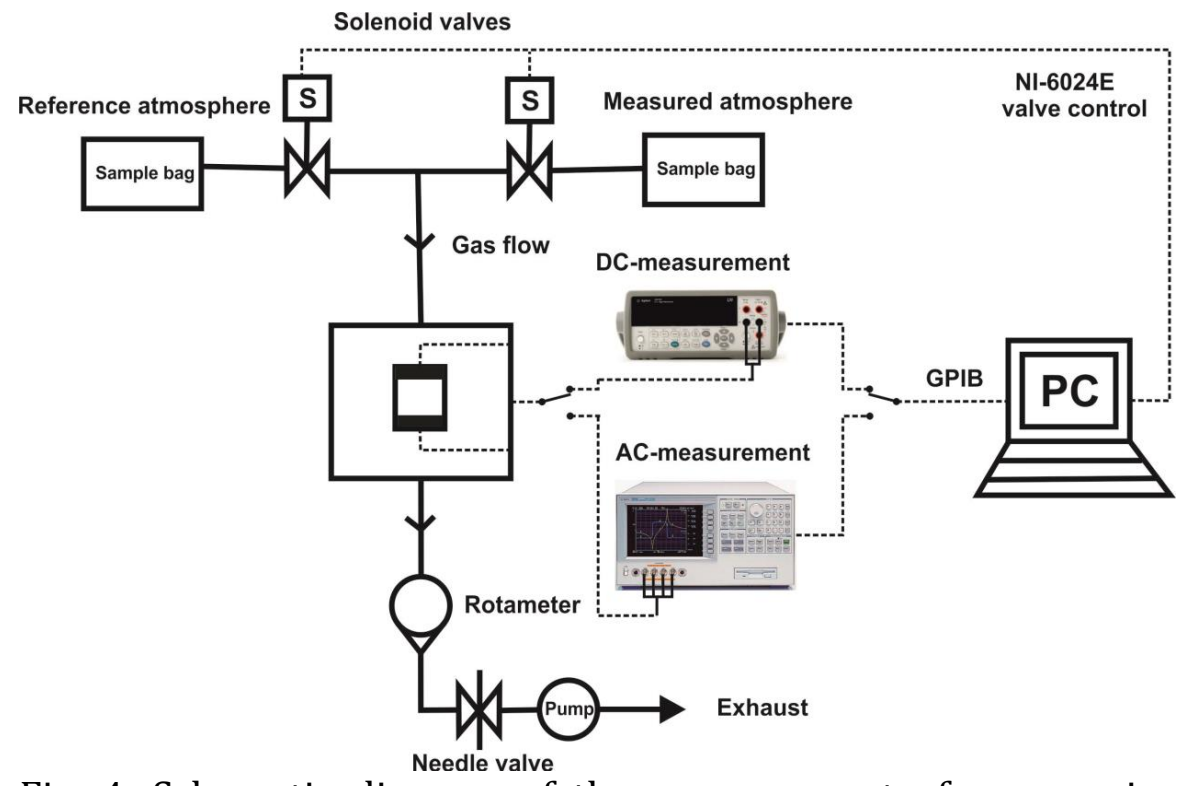

Fig. 4. Schematic diagram of the measurement of gas sensing properties. When studying the response in DC-mode, the measuring device is Agilent 34410A digital multimeter in 2-wire connection; in AC- mode we used Agilent 4294A impedance analyser in 4-wire connection. 


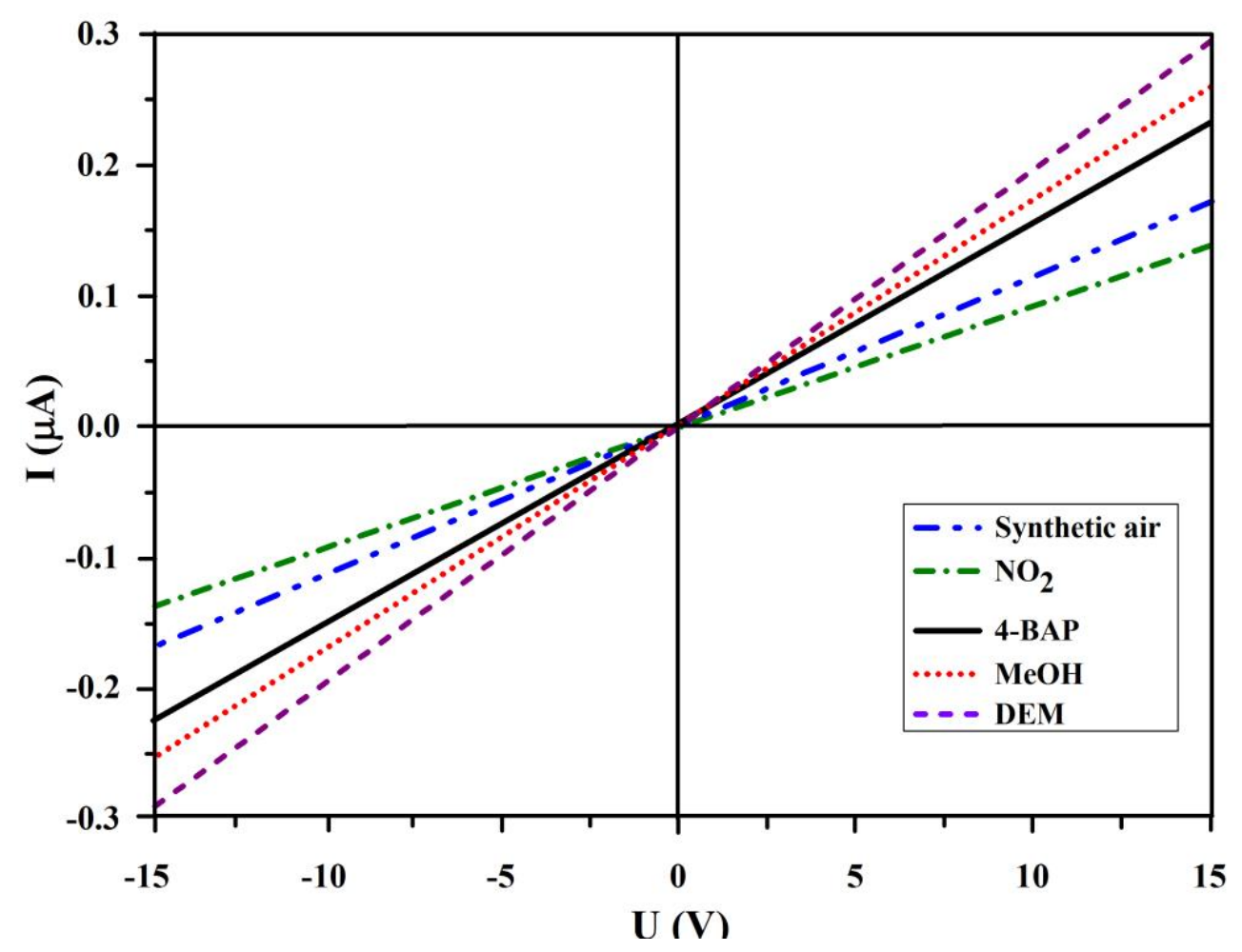

Fig. 5. V-I characteristics of the sensor A1 (Evolon - graphitic electrodes with 0.5 $\mathrm{mm}$ distance - poly( $\mathrm{P} 4,4,4,6 \mathrm{SPA})$ sensitive layer) at voltage from -15 to $+15 \mathrm{~V}$ under various atmospheres. All analytes were present in $10 \mathrm{ppm}$ concentration. There was also calculated the slope $(\mathrm{k})$ of line for each analyte: $\mathrm{DEM} \mathrm{k}=1.96 \times 10-8 \Omega-1 ; \mathrm{MeOH}$ $\mathrm{k}=1.72 \times 10-8 \Omega-1 ; 4-\mathrm{BAP} \mathrm{k}=1.55 \times 10-8 \Omega-1 ; \mathrm{NO} 2 \mathrm{k}=0.93 \times 10-8 \Omega-1$. 


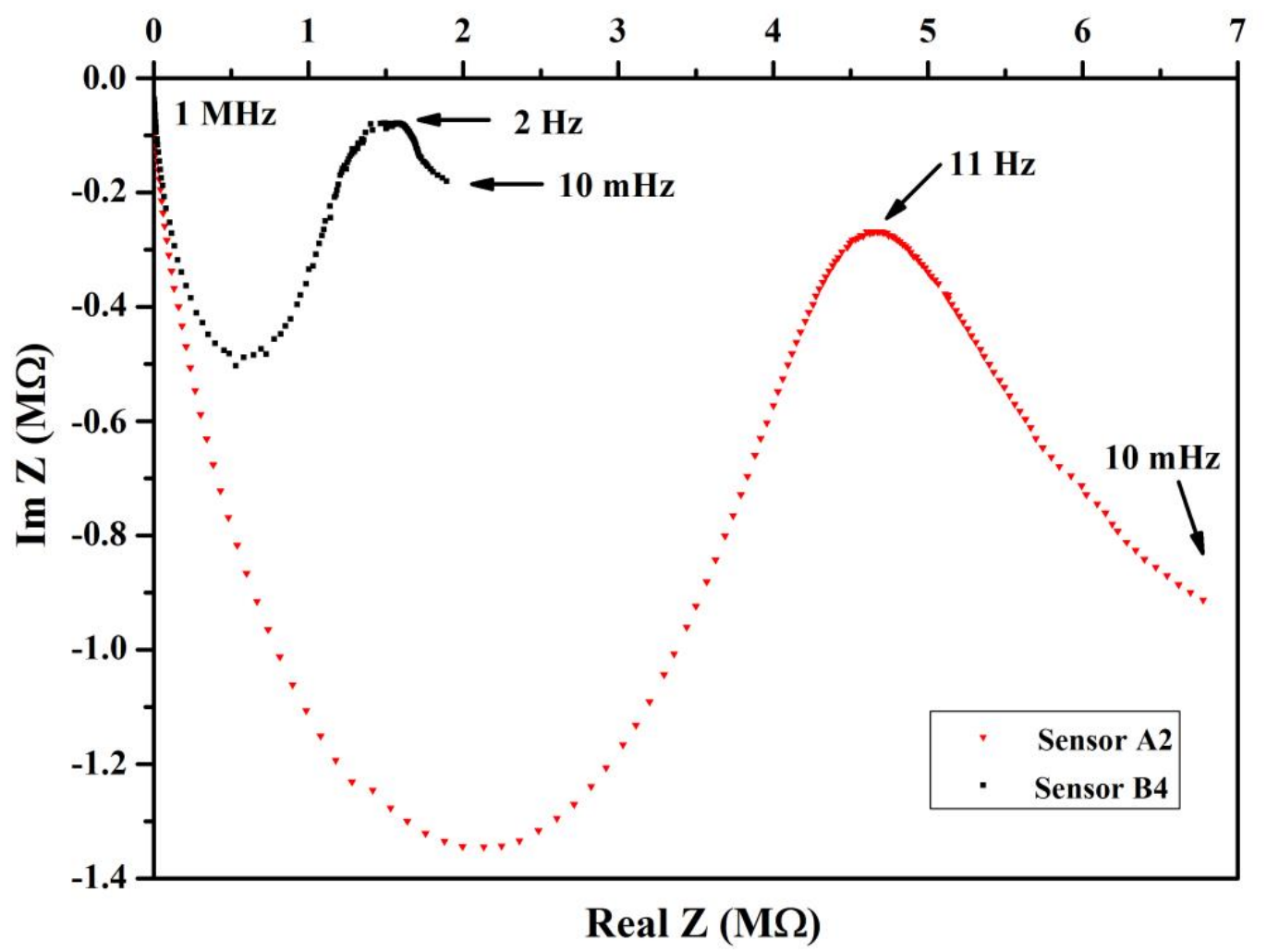

Fig. 6. Nyquist plot of impedance spectra of sensors A2 and B4 in frequency range from $10 \mathrm{mHz}$ to $1 \mathrm{MHz}$ measured under synthetic air.
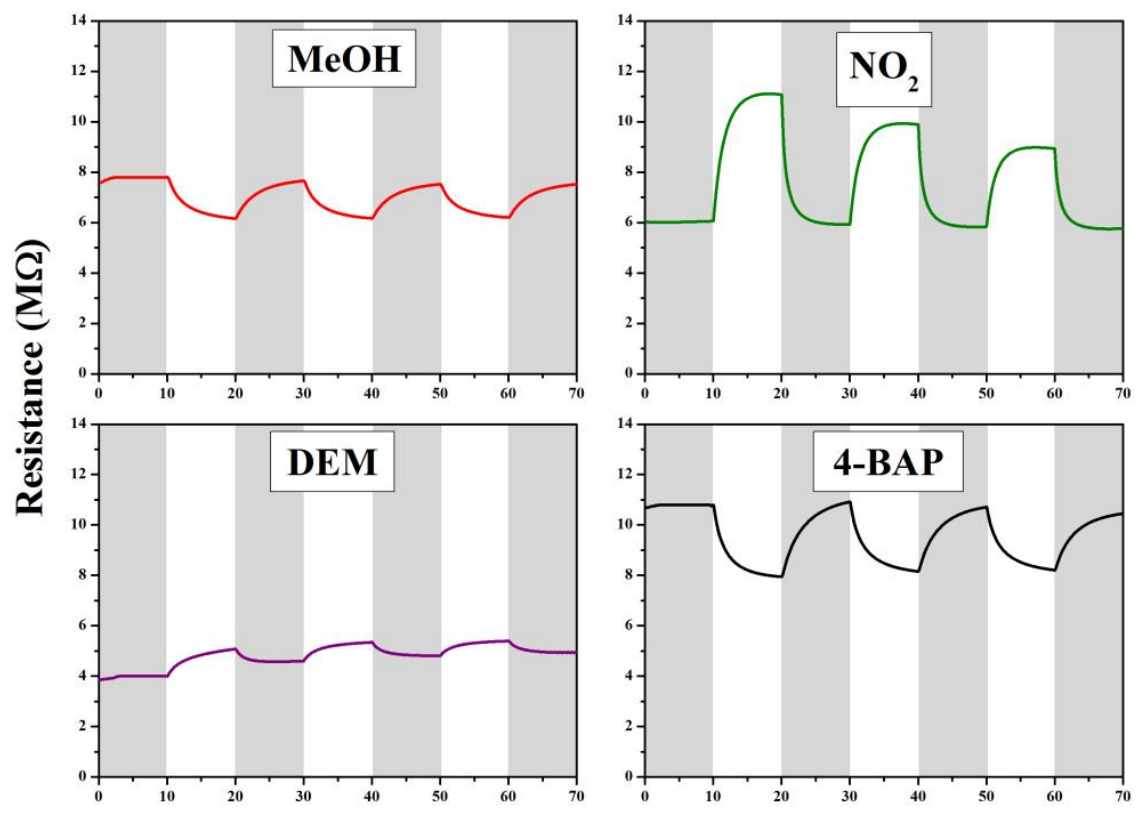

Time (min)

Fig. 7. DC-responses of sensor A1 to 10 ppm of nitrogen dioxide, 4bromoacetophenone, methanol and diethylmalonate. 


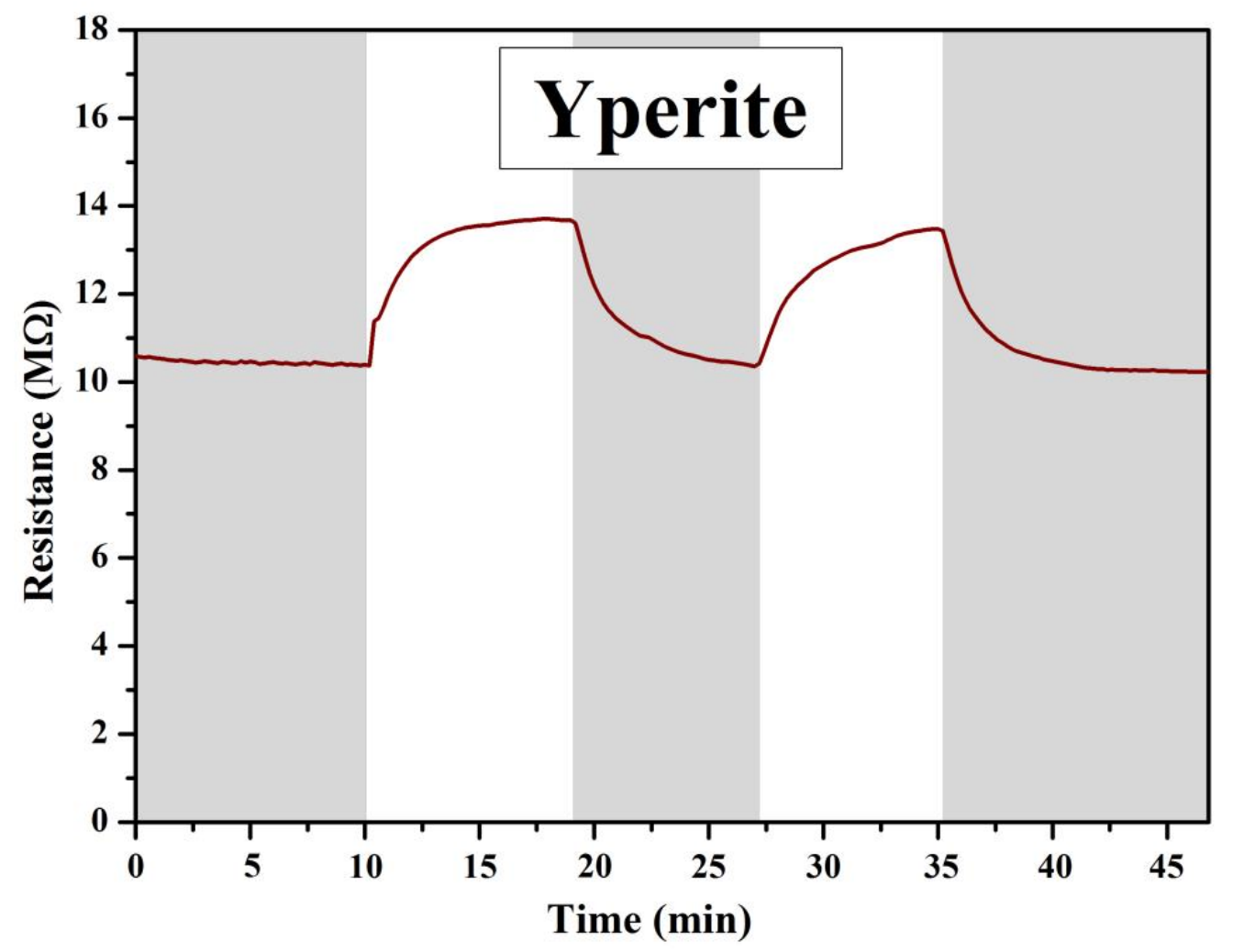

Fig. 8. Response of sensor A4 to $10 \mathrm{ppm}$ of yperite.

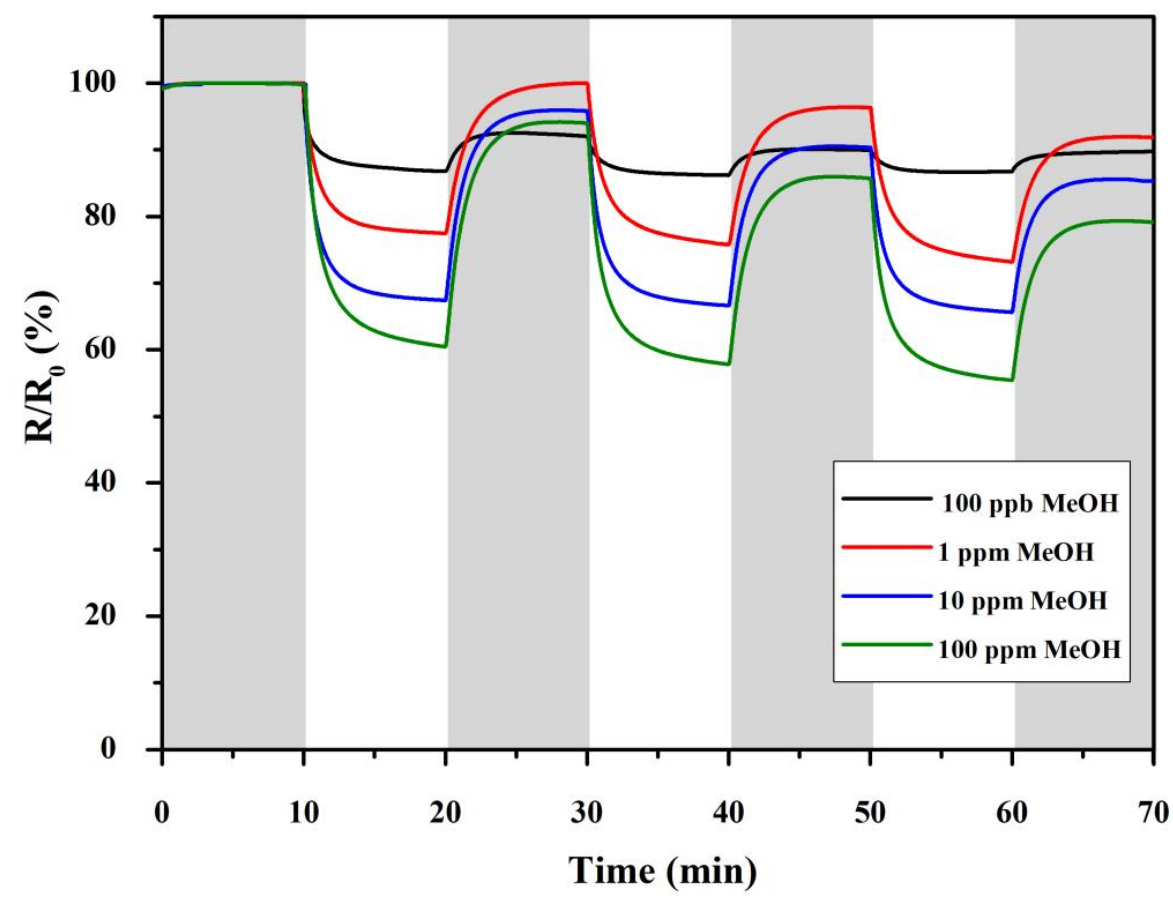

Fig.9. Response of sensor A1 to concentrations of $100 \mathrm{ppb}, 1 \mathrm{ppm}, 10 \mathrm{ppm}$ and 100 ppm methanol. 

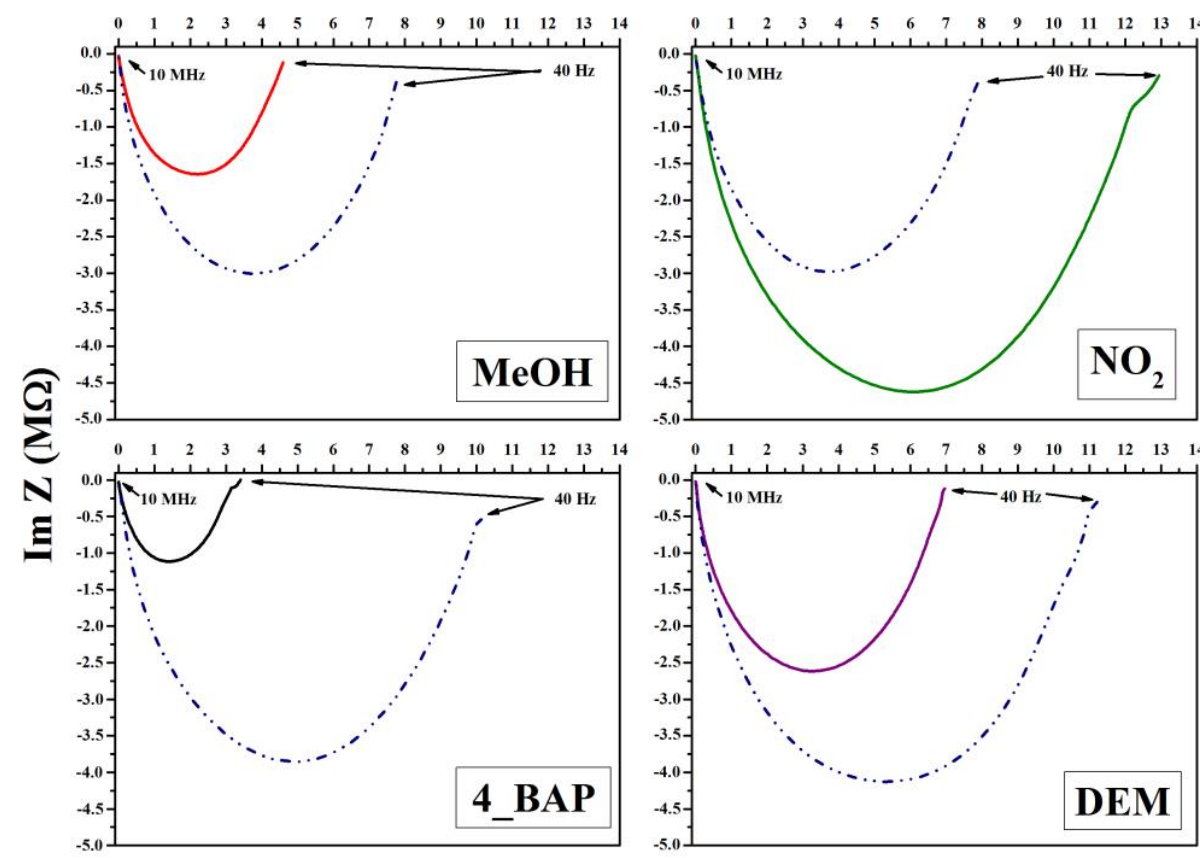

Real Z (M $\Omega)$

Fig. 10. Complex impedance (in the form of Nyquist plots) of the sensor B3 measured in frequency range $40 \mathrm{~Hz}-10 \mathrm{MHz}$ in distinct analytes. The curve corresponding to synthetic air has a dark-blue color in all plots.
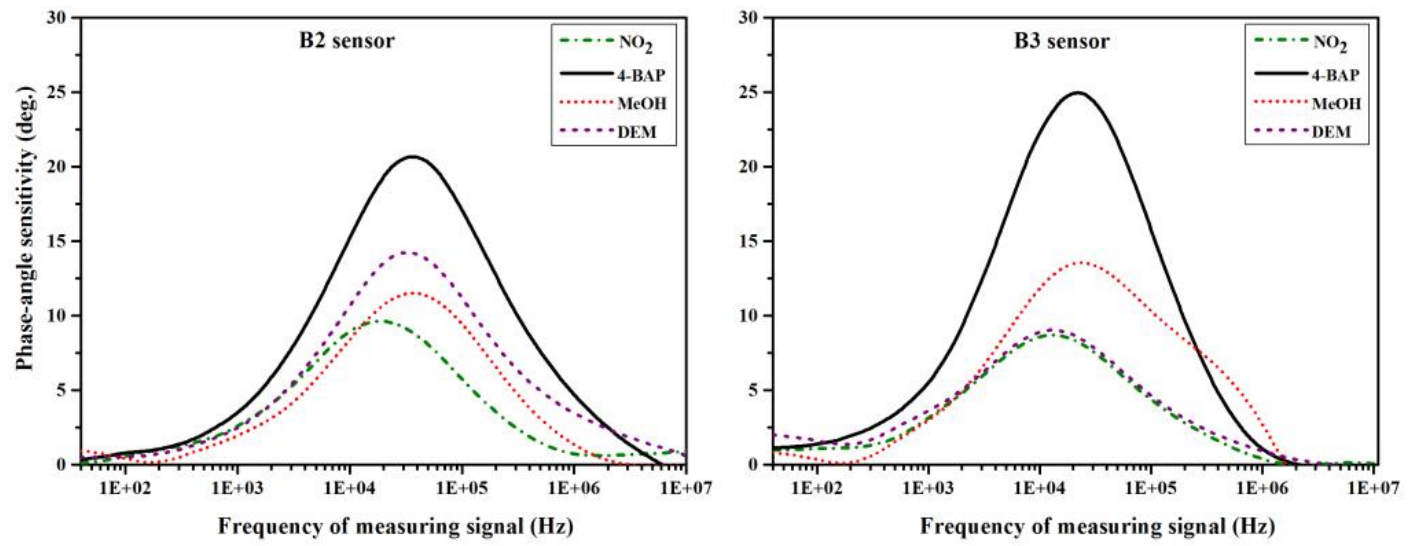

Fig. 11. The phase-angle sensitivity Spa of B2 and B3 in distinct analytes. 


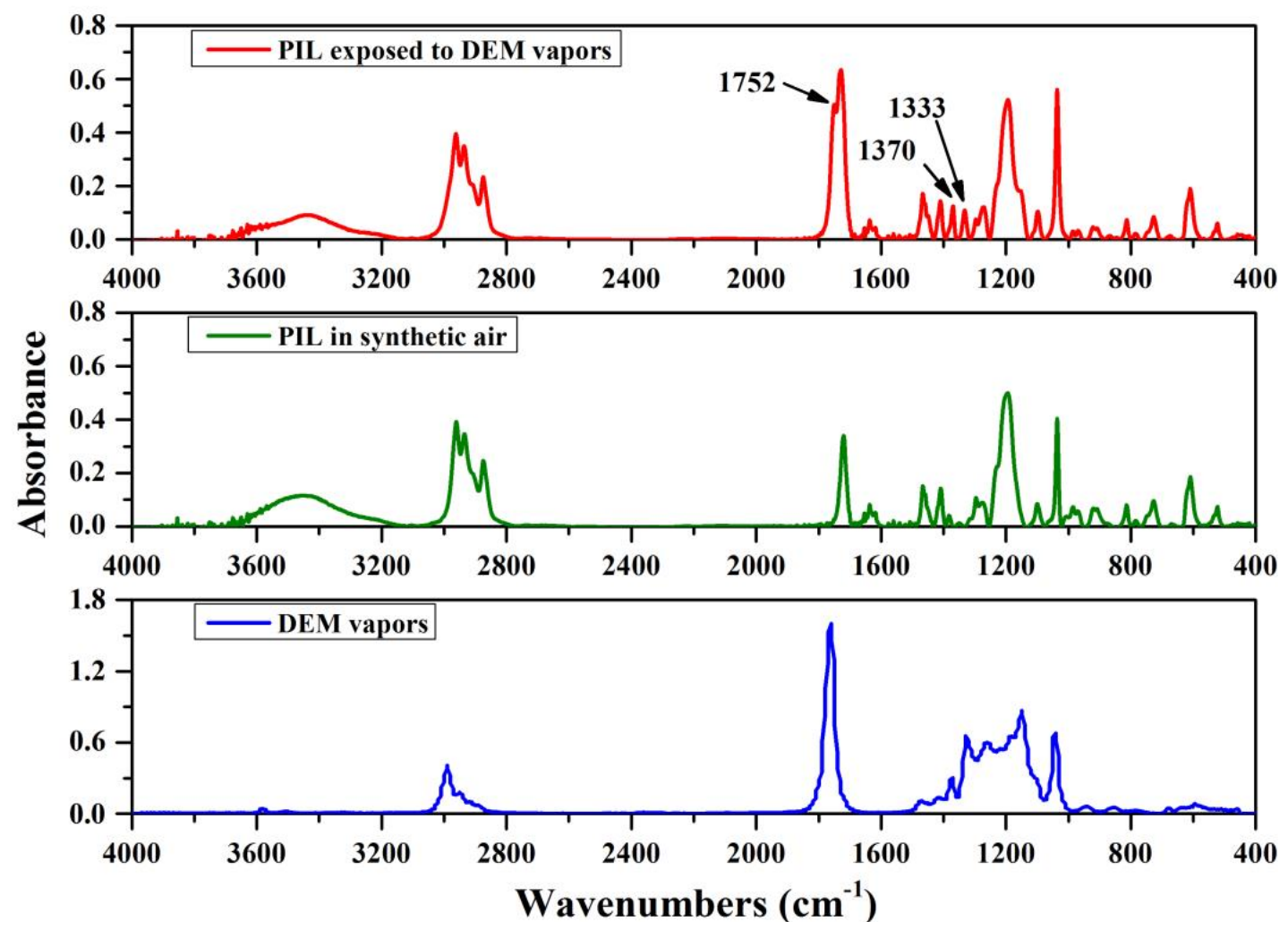

Fig. 12. The FTIR spectra of a) DEM vapors ; b) PIL in synthetic air; c) PIL exposed to DEM vapors. 